\title{
Ion-Pair Extraction by Use of Liquid Crystals as Extracting Solvent
}

\author{
Akira OHKI*, Shigeori Takenaka**, Kadzuya TsukadA**, Shigeru MaEdA* and Makoto Takagi** \\ * Department of Applied Chemistry, Faculty of Engineering, Kagoshima University, \\ Kagoshima 890, Japan \\ **Department of Organic Synthesis, Faculty of Engineering, Kyushu University, Fukuoka 812, Japan
}

\begin{abstract}
By using a liquid crystal, 4-cyano-4'-hexylbiphenyl (abbreviated as CHB), as an extracting solvent, the following ion-pair extraction reaction was investigated: $\left(\mathrm{Q}^{\cdot} \mathrm{ClO}_{4}\right)_{0}+\left(\mathrm{Pi}^{-}\right)_{\mathrm{w}} \rightleftharpoons(\mathrm{Q} \cdot \mathrm{Pi})_{\mathrm{o}}+\left(\mathrm{ClO}_{4}^{-}\right)_{\mathrm{w}}\left(\mathrm{Q}^{+}\right.$: cationic species such as Crystal Violet $\left(\mathrm{CV}^{+}\right)$, Methylene Blue $\left(\mathrm{MB}^{+}\right)$and tetrabutylammonium $\left(\mathrm{TBA}^{+}\right)$; $\mathrm{Pi}^{-}$: picrate anion; subscripts $\mathrm{O}$ and $\mathrm{w}$ denote organic and aqueous phases, respectively). The above extraction equilibrium was confirmed to hold in the case of a liquid crystal (CHB) solvent as well as in an ordinary solvent (hexylbenzene/cyanobenzene 1:1 mixture for comparison; abbreviated as MIX). The dependence of the extraction constant on the temperature was investigated. Only in the $\mathrm{CV}^{+}-\mathrm{CHB}$ system, the extraction constant discontinuously changed around a phase transition temperature of CHB $\left(29^{\circ} \mathrm{C}\right.$; nematic/liquid). When an MIX solvent was used, such a phenomenon was not observed; the extraction constant gradually increased with an increase in temperature. The effect of the molecular orientation of the extracting solvent is discussed.
\end{abstract}

Keywords Ion-pair extraction, extracting solvent, liquid crystal, phase transition

Liquid-liquid extraction of the ion-pair association complex (ion-pair extraction) is widely used in analytical and separation chemistry. ${ }^{1-3}$ The effect of the extracting solvent on the extractability has been one of the major subjects in studies concerning ion-pair extraction, and has usually been discussed in terms of solvent polarity, solubility parameter, and/or hydrogen-bonding power. ${ }^{4-10}$

However, the influence of the molecular shape and orientation of the solvent has not yet been studied.
Anisotropic liquids, such as liquid crystals, have not been used in ion-pair extraction reactions. A carriermediated liquid membrane transport has been reported which involves a polymer/liquid crystal composite membrane, being capable of thermocontrolling the transport rate via a solid-liquid crystal phase transition." However, the phase transition phenomena between the liquid crystal and an isotropic liquid have not yet been dealt with in solvent extractions and related studies.<smiles>CC(=O)c1ccc(-c2ccc(C#N)cc2)cc1</smiles><smiles>[X]C(C)(C)CCc1ccccc1C#N</smiles>

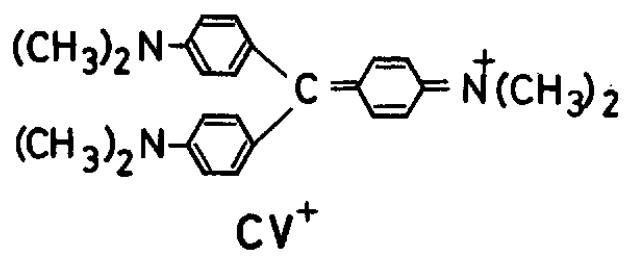<smiles>[13CH3]</smiles><smiles></smiles><smiles>O=[N+]([O-])c1cc([N+](=O)[O-])c([N+](=O)[O-])c([N+](=O)[O-])c1</smiles>

Fig. 1 Structures of solvents and ionic species used in this study. CHB, 4-cyano-4'-hexylbiphenyl; MIX, hexylbenzene/cyanobenzene 1:1 mixture; $\mathrm{CV}^{+}$, Crystal Violet; $\mathrm{TBA}^{+}$, tetrabutylammonium; $\mathrm{MB}^{+}$, Methylene Blue; $\mathbf{P i}^{-}$, picrate. 
In this study, we investigated the following extraction reaction by the use of liquid crystal as an extracting solvent:

$$
\left(\mathrm{Q} \cdot \mathrm{ClO}_{4}\right)_{\mathrm{o}}+\left(\mathrm{Pi}^{-}\right)_{\mathrm{w}} \stackrel{K_{\mathrm{ex}}}{\rightleftharpoons}(\mathrm{Q} \cdot \mathrm{Pi})_{\mathrm{o}}+\left(\mathrm{ClO}_{4}^{-}\right)_{\mathrm{w}},
$$

where $\mathrm{Q}^{+}$and $\mathrm{Pi}^{-}$represent a cationic species (Crystal Violet $\left(\mathrm{CV}^{+}\right)$, Methylene Blue $\left(\mathrm{MB}^{+}\right)$, and tetrabutylammonium $\left(\mathrm{TBA}^{+}\right)$) and picrate anion, respectively, and subscripts $o$ and $w$ denote the organic and aqueous phases, respectively. As a liquid crystal, 4-cyano-4'hexylbiphenyl (abbreviated as CHB) was used, which is a thermotropic liquid crystal in the nematic state around room temperature; the phase transition temperatures are $14^{\circ} \mathrm{C}$ (solid/nematic, $T_{\mathrm{SN}}$ ) and $29^{\circ} \mathrm{C}$ (nematic/liquid, $T_{\mathrm{NL}}$ ). The structutes of the solvents and ionic species used in this study are summarized in Fig. 1.

\section{Experimental}

\section{Reagents}

CHB (Merck) was purified by silica gel column chromatography (eluent: chloroform). Other chemicals were of reagent grade and were used without further purification.

\section{Extraction procedure}

An aqueous buffered solution $(1 \mathrm{ml} ; 10 \mathrm{mM}(\mathrm{M}=$ $\left.\mathrm{mol} / \mathrm{dm}^{3}\right) \mathrm{Na}_{2} \mathrm{CO}_{3}-\mathrm{NaHCO}_{3}$ buffer; $\mathrm{pH}$ 10) containing a $0.1 \mathrm{mM}$ cationic species $\left(\mathrm{CV}^{+}\right.$chloride, $\mathrm{MB}^{+}$chloride, or $\mathrm{TBA}^{+}$chloride), $0.1 \mathrm{mM}$ sodium picrate, and $10-$ $50 \mathrm{mM}$ sodium perchlorate was shaken with an organic solvent $(1 \mathrm{ml}$; CHB or mixed solvent (hexylbenzene/ cyanobenzene $1: 1$; abbreviated as MIX)) for $18 \mathrm{~h}$ in a thermostated bath $\left(15,20,25,30,35\right.$ or $\left.40^{\circ} \mathrm{C} ; \pm 0.1^{\circ} \mathrm{C}\right)$. After a phase-separation procedure was rapidly carried out, the concentration of the picrate in aqueous phase was determined by spectrophotometry $\left(\lambda_{\max }=358 \mathrm{~nm}\right)$ using a Hitachi 556 instrument.

\section{Results and Discussion}

\section{Extraction equilibrium}

The extraction constant, $K_{\mathrm{ex}}$, of reaction Eq. (1) can be given as

$$
K_{\mathrm{ex}}=[\mathrm{Q} \cdot \mathrm{Pi}]_{\mathrm{o}}\left[\mathrm{ClO}_{4}^{-}\right]_{\mathrm{w}} /\left[\mathrm{Q} \cdot \mathrm{ClO}_{4}\right]_{\mathrm{o}}\left[\mathrm{Pi}^{-}\right]_{\mathrm{w}}
$$

Equation (2) can be rewritten logarithmically as

$$
\begin{aligned}
\log \left(\left[\mathrm{ClO}_{4}^{-}\right]_{\mathrm{w}} /\left[\mathrm{Q} \cdot \mathrm{ClO}_{4}\right]_{\mathrm{o}}\right) \\
\quad=\log K_{\mathrm{ex}}-\log \left([\mathrm{Q} \cdot \mathrm{Pi}]_{\mathrm{o}} /\left[\mathrm{Pi}^{-}\right]_{\mathrm{w}}\right)
\end{aligned}
$$

The distribution of the cationic species, such as $\mathrm{MB}^{+}$ and $\mathrm{CV}^{+}$, into the aqueous phase was confirmed to be negligibly small when the extraction procedure was performed. Further, the concentration of perchlorate added to the aqueous phase was in large excess compared to that of other relatively lipophilic anions, such as chloride. Accordingly, when the extraction procedure is carried out, the reaction depicted in Eq. (1) is presumed to predominantly occur. Thus, $[\mathrm{Q} \cdot \mathrm{Pi}]_{\mathrm{o}}$, $\left[\mathrm{Q} \cdot \mathrm{ClO}_{4}\right]_{\mathrm{o}}$ and $\left[\mathrm{ClO}_{4}^{-}\right]_{w}$ are given as follows:

$$
\begin{aligned}
& {[\mathrm{Q} \cdot \mathrm{Pi}]_{\mathrm{o}}=\left[\mathrm{Pi}^{-}\right]_{\mathrm{w}, \text { initial }}-\left[\mathrm{Pi}^{-}\right]_{\mathrm{w}},} \\
& {\left[\mathrm{Q} \cdot \mathrm{ClO}_{4}\right]_{\mathrm{o}}=\left[\mathrm{Q}^{+}\right]_{\mathrm{w}, \text { initial }}-[\mathrm{Q} \cdot \mathrm{Pi}]_{\mathrm{o}},}
\end{aligned}
$$

and

$$
\left[\mathrm{ClO}_{4}^{-}\right]_{\mathrm{W}}=\left[\mathrm{ClO}_{4}^{-}\right]_{\mathrm{w}, \text { initial }}-\left[\mathrm{Q} \cdot \mathrm{ClO}_{4}\right]_{\mathrm{o}}
$$

Therefore, the values of $\log \left(\left[\mathrm{ClO}_{4}^{-}\right]_{\mathrm{w}} /\left[\mathrm{Q} \cdot \mathrm{ClO}_{4}\right]_{0}\right)$ and $\log \left([\mathrm{Q} \cdot \mathrm{Pi}]_{\mathrm{o}} /\left[\mathrm{Pi}^{-}\right]_{\mathrm{W}}\right)$ in Eq. (3) can be derived experimentally.

\section{Liquid crystal as an extracting solvent}

Figure 2 shows a plot of $\log \left(\left[\mathrm{ClO}_{4}^{-}\right]_{w} /\left[\mathrm{Q} \cdot \mathrm{ClO}_{4}\right]_{0}\right)$ against $-\log \left([\mathrm{Q} \cdot \mathrm{Pi}]_{o} /\left[\mathrm{Pi}^{-}\right]_{W}\right)$ in the extraction reactions performed at $25^{\circ} \mathrm{C}$ by use of a $\mathrm{CHB}$ solvent. Extraction reactions with the MIX solvent were carried out for a comparison, and the results are also indicated in Fig. 2; the solvent consists of hexylbenzene and cyanobenzene $(1: 1)$, which have fragmentary structures of the CHB molecule. All of the plots in Fig. 2 give straight lines with a slope of unity, suggesting that the reaction depicted in Eq. (1) is taking place exactly.

By considering the phase transition temperatures, $\mathrm{CHB}$ is in the nematic state at $25^{\circ} \mathrm{C}$. Thus, the extraction equilibrium, Eq. (1) proved to hold under the

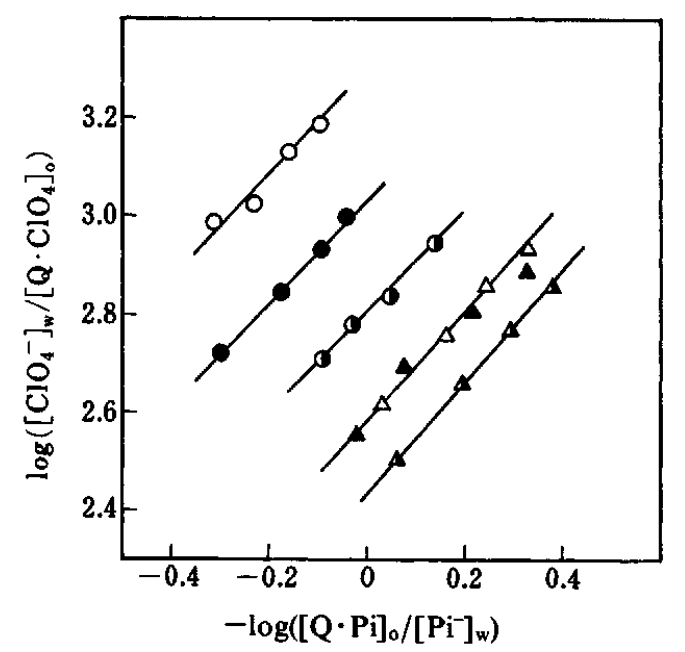

Fig. 2 Extraction equilibrium at $25^{\circ} \mathrm{C}$. O, $\mathrm{CV}^{+}-\mathrm{CHB} ;$ $\mathrm{MB}^{+}-\mathrm{CHB} ; 0, \mathrm{TBA}^{+}-\mathrm{CHB} ; \triangle, \mathrm{CV}^{+}-\mathrm{MIX} ; \triangle, \mathrm{MB}^{+}-\mathrm{MIX}$; $\Delta, \mathrm{TBA}^{+}-\mathrm{MIX}$ systems (e.g., $\mathrm{CV}^{+}-\mathrm{CHB}$ system means the extraction reaction Eq. (1) by use of $\mathrm{CV}^{+}$as $\mathrm{Q}^{+}$and of $\mathrm{CHB}$ as solvent). 
liquid crystal state of the solvent as well as in the ordinary solvent.

Table 1 summarizes the extraction constants $\left(\log K_{\text {ex; }}\right.$; at $25^{\circ} \mathrm{C}$ ) derived from Eq. (3). The liquid crystal solvent

Table 1 Extraction constant at $25^{\circ} \mathrm{C}\left(\log K_{\mathrm{ex}}\right)$

\begin{tabular}{ccc}
\hline \multirow{2}{*}{$\mathrm{Q}^{+}$} & \multicolumn{2}{c}{ Extracting solvent } \\
\cline { 2 - 3 } & CHB & MIX \\
\hline $\mathrm{CV}^{+}$ & 3.3 & 2.6 \\
$\mathrm{MB}^{+}$ & 3.0 & 2.6 \\
$\mathrm{TBA}^{+}$ & 2.8 & 2.4 \\
\hline
\end{tabular}

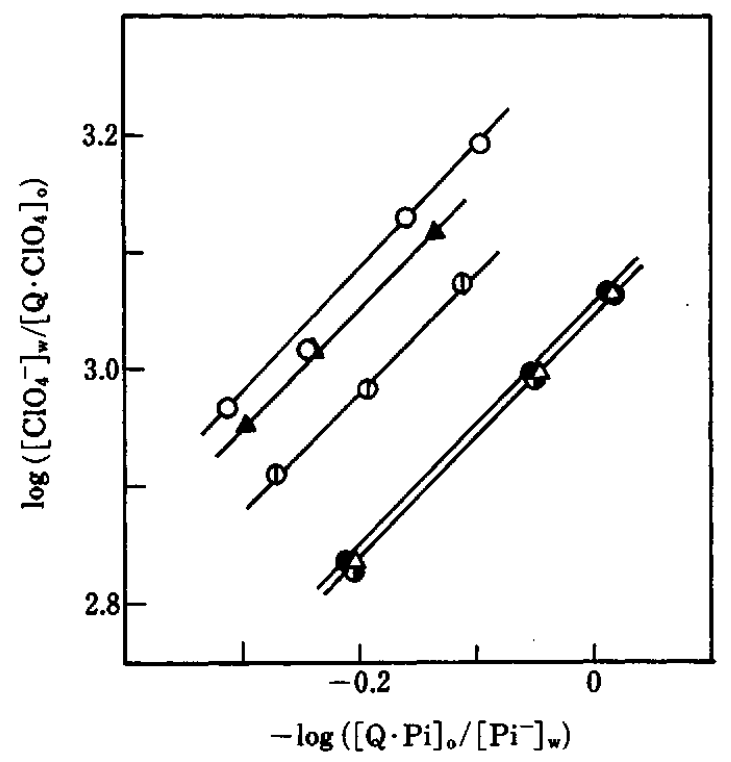

Fig. 3 Extraction equilibrium $\left(\mathrm{CV}^{+}-\mathrm{CHB}\right.$ system $)$ at various temperatures. $\Phi, 15^{\circ} \mathrm{C} ; \triangle, 20^{\circ} \mathrm{C} ; \mathrm{O}, 25^{\circ} \mathrm{C} ; 0,30^{\circ} \mathrm{C} ; \triangle, 35^{\circ} \mathrm{C}$; O, $40^{\circ} \mathrm{C}$.

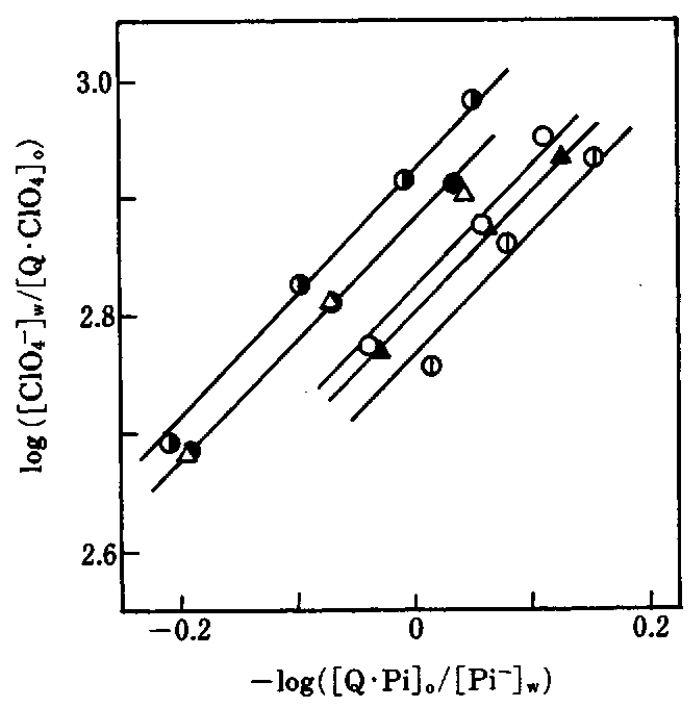

Fig. 4 Extraction equilibrium ( $\mathrm{TBA}^{+}-\mathrm{CHB}$ system) at various temperatures. Symbols are the same as those in Fig. 2.
(CHB) tended to exhibit a higher extraction constant than the MIX solvent in all three systems of $\mathrm{CV}^{+}, \mathrm{MB}^{+}$ and $\mathrm{TBA}^{+}$.

\section{Temperature dependence of the extraction reaction}

Figure 3 shows a plot of $\log \left(\left[\mathrm{ClO}_{4}^{-}\right]_{\mathrm{w}} /\left[\mathrm{Q} \cdot \mathrm{ClO}_{4}\right]_{0}\right)$ against $-\log \left(\left[\mathrm{Q} \cdot \mathrm{Pi}_{\mathrm{o}} /\left[\mathrm{Pi}^{-}\right]_{w}\right)\left(\mathrm{Q}^{+}=\mathrm{CV}^{+}\right)\right.$performed at various temperatures $\left(15-40^{\circ} \mathrm{C}\right)$. Similar plots for the extraction reaction $\left(\mathrm{Q}^{+}=\mathrm{TBA}^{+}\right)$are indicated in Fig. 4 . All of the plots in Figs. 3 and 4 are straight lines with a slope of unity. It was found that the extraction equilibrium did not change under the temperature conditions $\left(15-40^{\circ} \mathrm{C}\right)$, i.e., Eq. (1) holds both under the liquid crystal state of $\mathrm{CHB}$ and under the liquid state of CHB.

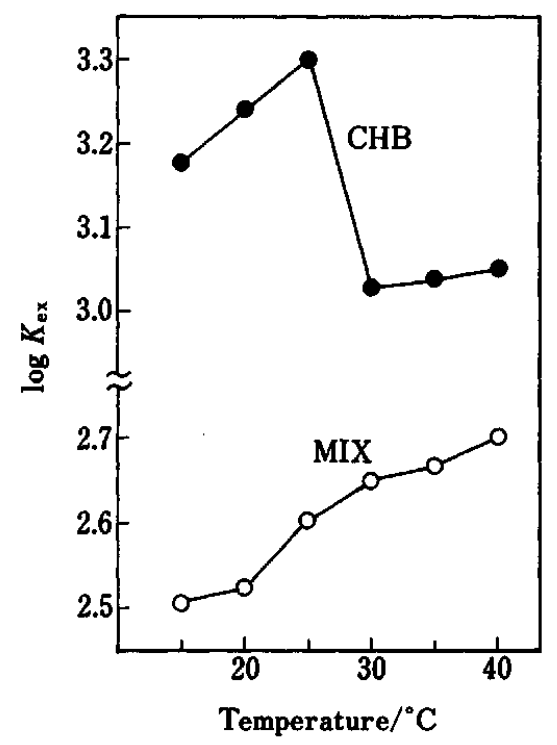

Fig. 5 Dependence of $\log K_{\text {ex }}$ on temperature $\left(\mathrm{Q}^{+}=\mathrm{CV}^{+}\right)$. $\mathrm{CHB}(O)$ and MIX $(O)$ were used as solvent.

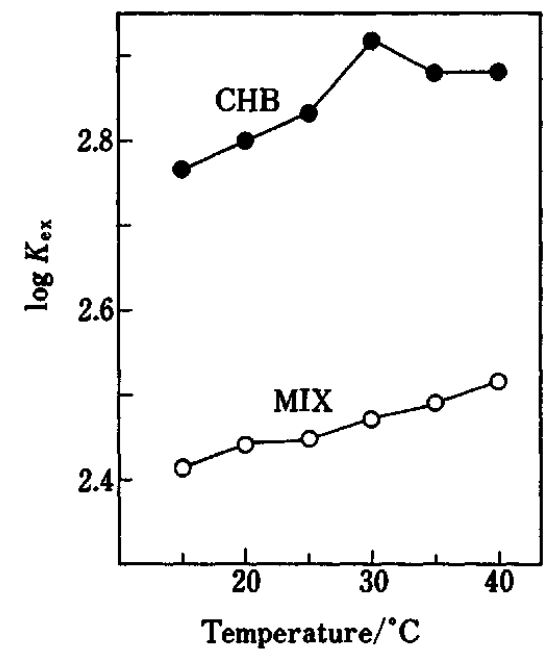

Fig. 6 Dependence of $\log K_{\mathrm{ex}}$ on temperature $\left(\mathrm{Q}^{+}=\mathrm{TBA}^{+}\right)$. $\mathrm{CHB}(O)$ and $\operatorname{MIX}(O)$ were used as solvent. 


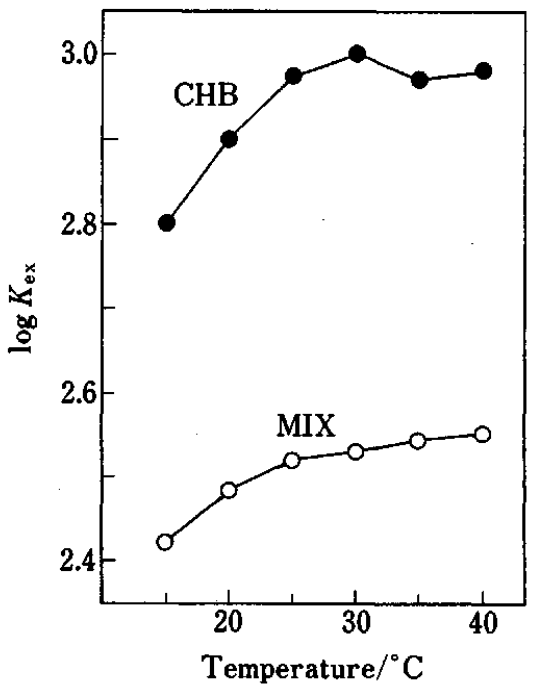

Fig. 7 Dependence of $\log K_{\mathrm{ex}}$ on temperature $\left(\mathrm{Q}^{+}=\mathrm{MB}^{+}\right)$. CHB (O) and MIX (O) were used as solvent.

The values of $\log K_{\mathrm{ex}}$ in the $\mathrm{CV}^{+}-\mathrm{CHB}$ system and in the TBA $^{+}-\mathrm{CHB}$ system are graphically summarized in Figs. 5 and 6 as a function of the temperature, respectively. In the case of the $\mathrm{CV}^{+}-\mathrm{CHB}$ system (below $T_{\mathrm{NL}} ; 15-25^{\circ} \mathrm{C}$ ), the extraction constant gradually increased with an increase in the temperature, whereas a considerable depression in the $\log K_{\mathrm{ex}}$ value was observed near $T_{\mathrm{NL}}\left(29^{\circ} \mathrm{C}\right)$. However, in the $\mathrm{TBA}^{+}-\mathrm{CHB}$ system, such a depression in $\log K_{\mathrm{ex}}$ was not observed; the extraction constant gradually increased between $15-30^{\circ} \mathrm{C}$, while slightly decreasing above $30^{\circ} \mathrm{C}$.

The temperature dependence of the extraction reaction, the $\mathrm{MB}^{+}-\mathrm{CHB}$ system, was also investigated (Fig. 7) 12 , indicating a similar behavior to that observed in the $\mathrm{TBA}^{+}-\mathrm{CHB}$ system. Further, we investigated the temperature dependence of the extraction reactions by the use of a MIX solvent; Figs. 5, 6 and 7 additionally display the plots of $\log K_{\text {ex }}$ against temperature in the $\mathrm{CV}^{+}-\mathrm{MIX}$ system, the $\mathrm{TBA}^{+}-\mathrm{MIX}$ system and the $\mathrm{MB}^{+}-\mathrm{MIX}$ system, respectively. ${ }^{12}$ The extraction constants in these systems were slowly increased throughout all temperatures used.

\section{Molecular orientation effect of the extracting solvent}

In the case of the $\mathrm{CV}^{+}-\mathrm{CHB}$ system, the extraction behavior were remarkably different from each other under the anisotropic liquid crystal state and under the isotropic liquid state (Fig. 5). It is considered that the phase transition of the solvent causes a destruction of the molecular orientation and a variation in the chemical and physical properties, such as the dielectric constant, leading to a change in the extraction constant. The extraction reaction, Eq. (1), is an anion-exchange reaction between spherical (in shape) perchlorate and plane (in shape) picrate. The extractability of picrate was higher in the liquid crystal state than in the liquid state. Further, as can be seen in Table 1 , the $\mathrm{CV}^{+}-\mathrm{CHB}$ system exhibited a higher extractability compared to other systems. These results suggest that the highly plane shaped ion-pair complex, $\mathrm{CV}^{+}$-picrate, favors liquid crystal state solvents to liquid state solvents.

In both the $\mathrm{TBA}^{+}-\mathrm{CHB}$ system and the $\mathrm{MB}^{+}-\mathrm{CHB}$ system, no distinct change in the extraction behavior was observed at $T_{\mathrm{NL}}$; the extraction constant was gradually increased with an increase in the temperature, being almost constant above $T_{\mathrm{NL}}$ (Figs. 6 and 7). The ion-pair complexes formed with $\mathrm{TBA}^{+}$and $\mathrm{MB}^{+}$are considered to be less plane in shape than that with. $\mathrm{CV}^{+}$; this would account for the lack of distinct behavior change at $T_{\mathrm{NL}}$.

When the MIX solvent was used, such a plateau part of the plot (above $T_{\mathrm{NL}}$ ) was not observed, i.e., the increase in $\log K_{\mathrm{ex}}$ continued throughout all temperatures (Figs. 5-7). Accordingly, it seems adequate that, even in the $\mathrm{TBA}^{+}-\mathrm{CHB}$ system and the $\mathrm{MB}^{+}-\mathrm{CHB}$ system, the effect of the phase transition of the solvent exists to some extent.

In this study, by using a liquid crystal as the extracting solvent, we have verified the effect of the molecular orientation of a solvent on the ion-pair extraction reaction. Anisotropic liquids, such as liquid crystal, have not been used in solvent extraction studies. Rather little consideration has been given to the structural aspects of the extracting solvent, such as the effects of molecular shape and orientation. Obviously, the novel-type solvent effect presented in this study may open a new possibility in solvent extraction chemistry (e.g., thermocontrol of the extractability), which certainly deserves further exploration.

\section{References}

1. K. Tôei, Anal. Chem., 3, 479 (1987).

2. H. Green, Talanta, 20, 139 (1973).

3. K. L. Cheng, K. Ueno and T. Imamura, "Handbook of Organic Analytical Reagents", CRC Press, Boca Raton, 1982.

4. R. Diamond and J. Bucker, J. Phys. Chem., 69, 1565 (1965).

5. W. Müller and R. Diamond, J. Phys. Chem., 70, 3469 (1966).

6. H. Freiser, Anal. Chem., 41, 1354 (1969).

7. T. Higuchi, A. Michaels and J. H. Rytting, Anal. Chem., 43, 287 (1971).

8. H. M. N. H. Irving and R. H. Al-Jarrah, Anal. Chim. Acta, 63, 79 (1973).

9. E. Iwamoto, K. Ito and Y. Yamamoto, J. Phys. Chem., 85, 894 (1981).

10. A. Ohki, X-L. Xiao, Y. Fujino and M. Takagi, Anal. Sci., 2, 293 (1986).

11. S. Shinkai, K. Torigoe, O. Manabe and T. Kajiyama, $J$. Am. Chem. Soc., 109, 4458 (1987).

12. It was confirmed in several runs that the extraction equilibrium, Eq. (1), exactly occurred.

(Received October 18, 1989)

(Accepted November 24, 1989) 